\title{
CFD Analysis of Tensile Conical Membrane Structures as Microclimate Modifiers in Hot Arid Regions
}

\author{
Amira M. Elnokaly \\ Lincoln School of Architecture, College of Arts, University of Lincoln, Brayford Pool, Lincoln, LN6 7TS, United Kingdom \\ *Corresponding Author : aelnokaly@lincoln.ac.uk
}

Copyright (C) 2014 Horizon Research Publishing All rights reserved.

\begin{abstract}
Extensive research has been undertaken to understand form finding and the structural behaviour of tensile membrane structures (TMS). In comparison, little is known about the environmental behaviour of this class of structure and a lack of predictive tools for informing their design serves as a barrier to their wider acceptance by the building industry. This paper presents part of a research study carried out to investigate the effect of various forms, configurations and orientations of conical TMS on the airflow behaviour under, around and above these structures for application in hot arid climates. The airflow behaviour and airspeed in an enclosed or semi-enclosed space significantly influence thermal comfort in hot-arid climates. Part of this research involved a parametric study of the airflow behaviour of conical TMS scaled models with different geometrical configurations and orientations in an environmental wind tunnel. The results of this experimental investigation were compared with results from investigations carried out in computational fluid dynamics (CFD) software "FLUENT 5.5" on 1:20 and 1:1 models. The comparison showed that the CFD modelling was able to replicate much of the behaviour observed in the wind tunnel and the approach was extended to explore arrays of conical TMS. This paper presents the CFD modelling undertaken to explore airflows over varying conical tensile fabric structures. The modelling is carried over single conical structures either inverted or straight. These investigations explore how the form, geometry and orientation of a conical TMS affect the airflow rates. The paper concludes with a discussion of how the form and geometrical configuration affect the airflow behaviour and hence the thermal comfort level of the occupants of the semi-enclosed space.
\end{abstract}

Keywords Tensile Membrane Structures, Airflow, Environmental Behaviour, Comfort Level, CFD Modelling, Wind Tunnel Investigation

\section{Introduction}

It is impractical to research on Tensile Membrane
Structures (TMS) and not mention Frei Otto [1] a German Architect, a pioneer who have carried out extensive research and investigations to understand form finding and the structural behaviour of (TMS). Many public facitilities such as urban furniture and bus stations are increasingly constructed of membrane structures today. In addition to them being light weight, transparent and easy to erect for a large space they are highly solar-reflective and thin membrane materials absorb little solar heat and keep their surface temperatures low when irradiated by solar radiation . Furthermore a semi-enclosed (semi-outdoor) space can also be created under these membrane structures. [2, 3] As a result, both day lighting and natural ventilation can be provided. With their multiple potentials a membrane structure building would play an attractive role in improving outdoor thermal environments and mitigating the heat island effect in the developed urban locations [4, 5]

Many previous studies have been carried out on membrane structure buildings with enclosed indoor spaces such as atrium and dome spaces where air-conditioning is required. [6, 7] As one of these previous studies, Kim et al. [8, 9] carried out an empirical investigation into indoor environments and air exchange rate in arcade-type markets with different building sizes and roof materials. At present there is still a lack of studies on membrane structure buildings with semi-outdoor spaces that are not air-conditioned zones. [5, 9 \& 10]

This research has been carried out on various conical tensile fabric forms being the most popular roof form used in hot arid regions [11]; in this paper the conical roof form will be discussed in more detail. Knowledge of the airflow pattern and rate in and around fabric membrane structures and their effect on the comfort level within the space is still relatively unexplored compared with that in more conventional structures. [12]

As with conventional buildings, understanding of airflow rate and pattern around these structures is of vital importance in order to assess if comfort levels are appropriate during the design process. [13, $14 \& 15]$ It is the aim of this study to improve the understanding of airflow behaviour around and under conical membrane structures to assist in their design and application as micro-climate modifiers. 
The reason for using CFD modelling is to ascertain the use of CFD modelling and its reliability in predicting and understanding airflow in spaces enclosed or semi-enclosed by FMS. In addition to that this work was undertaken to provide an opportunity to explore different geometries and more combinations of conical units than would be possible using the experimental laboratory work alone. This will give the opportunity of using these techniques with more confidence, instead of using physical modelling, that are by far more time consuming, and much more expensive to run [3].

\section{Application of CFD in Ventilation and Airflow around Buildings}

Advanced building design requires information about airflow in and around buildings in order to assess thermal comfort and indoor air quality [13]. Heating, Ventilation and Air Conditioning (HVAC) units are humdrum in medium and large building and multioccupancy spaces. It is estimated that nearly $68 \%$ of the total energy used in service and residential buildings attributable to these common systems. [15] However, with the drive to reduce the demand for energy, architects, designers and engineers are now attempting to return to the utilisation of natural ventilation wherever possible. [14] The most common procedures for investigating airflow behaviour around buildings or in urban areas are wind tunnel modelling and field measurements which as discussed earlier is much more time consuming to run compared to computer simulation. Computational fluid dynamics (CFD) offers an alternative to these traditional approaches, and facilitates a numerical rather than physical simulation of the flow variables [16 and 17]. The airflow around bluff bodies and structures located in the atmospheric environment is complex and difficult to analyze. Its behaviour can differ significantly from one case to another, compared with flow in a pipe or channel. [18] These airflow patterns are important factors in predicting wind effects on structures and their immediate vicinity. [19]

\subsection{The Choice of Form and Models Tested}

The conic shape was selected as a test case to explore the behaviour of structures such as those shown in Fig. (1); these being one of the simplest and most frequently used fabric structure roof forms. Studies suggest that the use of fabric structures for outdoor and intermediate spaces can have a positive effect on the modification of the microclimate underneath it. [20,21] This study utilized a CFD programme FLUENT 5.5 [16, 22] for investigating the airflow around such structures. Following a series of wind tunnel experiments that were undertaken to visualize the airflow pattern, CFD modelling results were investigated and validated by the results from the wind tunnel tests. The tests were designed to explore the effect the form of the roof has on the airflow, in order to inform the design of structures that enhance the natural ventilation and passive cooling of the semi-enclosed space.

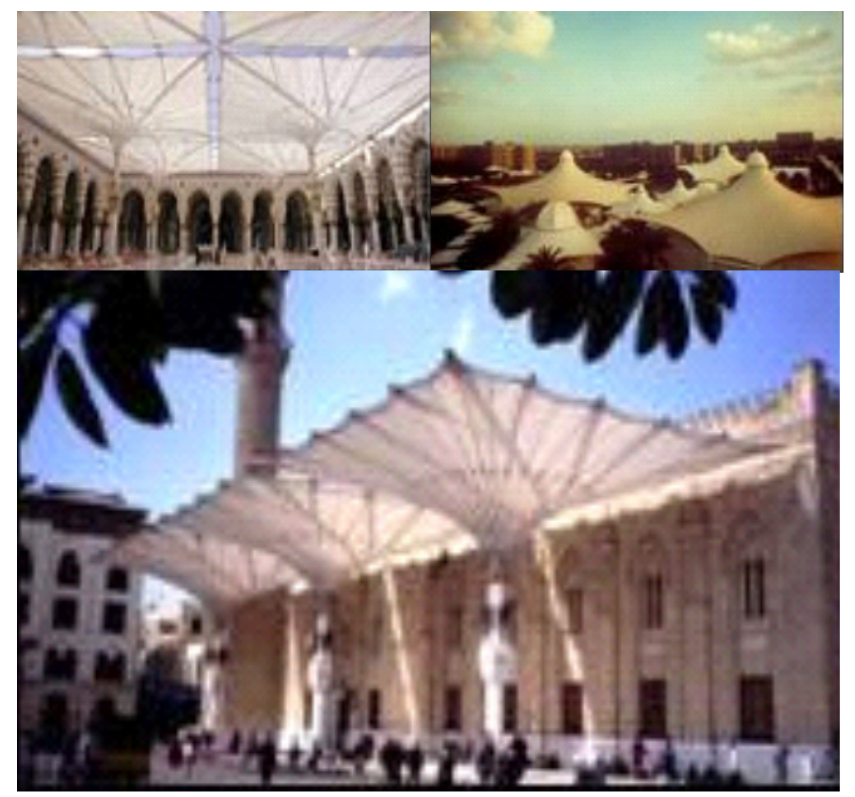

Figure 1. The use of conical membrane structures in different architectural projects (Photo courtesy TENSINET Library [23])

1:20 scale models of conical membranes were used in both the wind tunnel and the CFD modelling. The 1:20 scale conical membrane model was used in different configurations and positions (straight, tilted, inverted) and with different heights, some of the modeled configurations are discussed in this paper. The same heights and dimensions used in the wind tunnel was tested in the CFD programme FLUENT in order to validate the CFD results. In both the wind tunnel and the CFD the cones were tested as straight, inverted and tilted, with either closed or open apex in all cases. Also the same conditions were set testing a flat disc with the same diameter as the cones and at the same height from the ground. A normal condition was also monitored where the air velocities were monitored in both the wind tunnel and CFD model with no structure at all in order to be used as a zero (reference) condition. For further validation of results a full scale model was built and tested in FLUENT 5.5. The results of this investigation were analysed and compared with data from the scaled models. In total a number of 64 different cases were tested. Figure 2 depicts some of the cases presented in this paper and tested in the CFD modelling.

\section{Methodology}

\section{CFD Investigation; 2D Modelling}

To carry out CFD modelling in FLUENT first a 2D model was built in order to observe the behaviour of the airflow and its pattern to be compared to the wind tunnel results. 
The airflow pattern showed very similar trends to the ones shown in the wind tunnel visualization which raised greater interest in building models in 3D and testing them as shown in Figs. (3).

\begin{tabular}{|c|c|c|c|}
\hline CASES & Apex & Height of cone & Tilt \\
\hline Test 1 & Closed & $17 \mathrm{~cm}$ & None \\
\hline Test 2 & Opened & $17 \mathrm{~cm}$ & None \\
\hline Test 3 & Closed & $17 \mathrm{~cm}$ & $\begin{array}{l}\text { Tilted towards } \\
\text { the wind }\end{array}$ \\
\hline Test 4 & Closed & $17 \mathrm{~cm}$ & $\begin{array}{l}\text { Tilted away } \\
\text { from the wind }\end{array}$ \\
\hline Test 5 & Closed & $17 \mathrm{~cm}$ & $\begin{array}{l}\text { Tilted on the } \\
\text { right }\end{array}$ \\
\hline Test 6 & Closed & $17 \mathrm{~cm}$ & Tilted on the left \\
\hline Test 7 & Opened & $17 \mathrm{~cm}$ & $\begin{array}{l}\text { Tilted towards } \\
\text { the wind }\end{array}$ \\
\hline Test 8 & Opened & $17 \mathrm{~cm}$ & $\begin{array}{l}\text { Tilted away } \\
\text { from the wind }\end{array}$ \\
\hline Test 9 & Opened & $17 \mathrm{~cm}$ & $\begin{array}{l}\text { Tilted on the } \\
\text { right }\end{array}$ \\
\hline Test 10 & Opened & $17 \mathrm{~cm}$ & Tilted on the left \\
\hline Test 11 & Closed & $17 \mathrm{~cm}$ & Inverted Cone \\
\hline Test 12 & Closed & $3 \mathrm{~cm}$ & Inverted Cone \\
\hline Test 13 & Opened & $17 \mathrm{~cm}$ & Inverted Cone \\
\hline Test 14 & Opened & $3 \mathrm{~cm}$ & Inverted Cone \\
\hline Test 15 & No Structure & No Structure & No Structure \\
\hline Test 16 & Notapplicable & Flat disc $=3 \mathrm{~mm}$ & None \\
\hline
\end{tabular}

Figure 2. Some cases modelled in CFD, Tilted cases are in relation to the airflow inlet direction

Where inverted cone
and straight cone $=$

The type of airflow in the wind tunnel experiments was calculated in order to know the type of flow associated with it. This was carried out using Reynolds number and verified as a turbulent flow [24]. This is essential to be confirmed at an early stage in order to use the right model in FLUENT 3 we. The Reynolds number of the model was calculated using Eqn. (1) and the flow was found to be turbulent. Therefore, the turbulent model k- $\varepsilon$ was used to model the structure. The $\mathrm{k}-\varepsilon$ model is believed to be the most widely used model for solving turbulent flows around buildings [25].

Reynolds Number, Re, can be expressed as:

$$
\operatorname{Re}=\frac{D \cdot v \cdot \rho}{\mu}
$$

where

$D=$ characteristic length $(\mathrm{m})$

$v=$ velocity $(\mathrm{m} / \mathrm{s})$

$\rho=$ density $\left(\mathrm{kg} / \mathrm{m}^{3}\right)$

$\mu=$ dynamic (absolute) viscosity (N.s $\left./ \mathrm{m}^{2}\right)$
$G=$ mass velocity $(\mathrm{m} / \mathrm{s})$

Fig. 3 (a) illustrates velocity magnitude contours for a vertical section in the mid axis of Test 1 , which indicate a relatively stagnant zone within the cone and high velocities in the inhabited area. This behaviour follows that revealed in the wind tunnel visualization tests shown in Fig. 3 (b). For a conical membrane with a closed apex, the airflow tends to be deflected downwards into the occupied area then deflects back upwards again when leaving the area underneath the structure as seen in Fig 3 (a \& b). The results were the same in all the tested cases of the closed apex cones, with the deflection of flow appearing to become more pronounced as the cone height was increased.

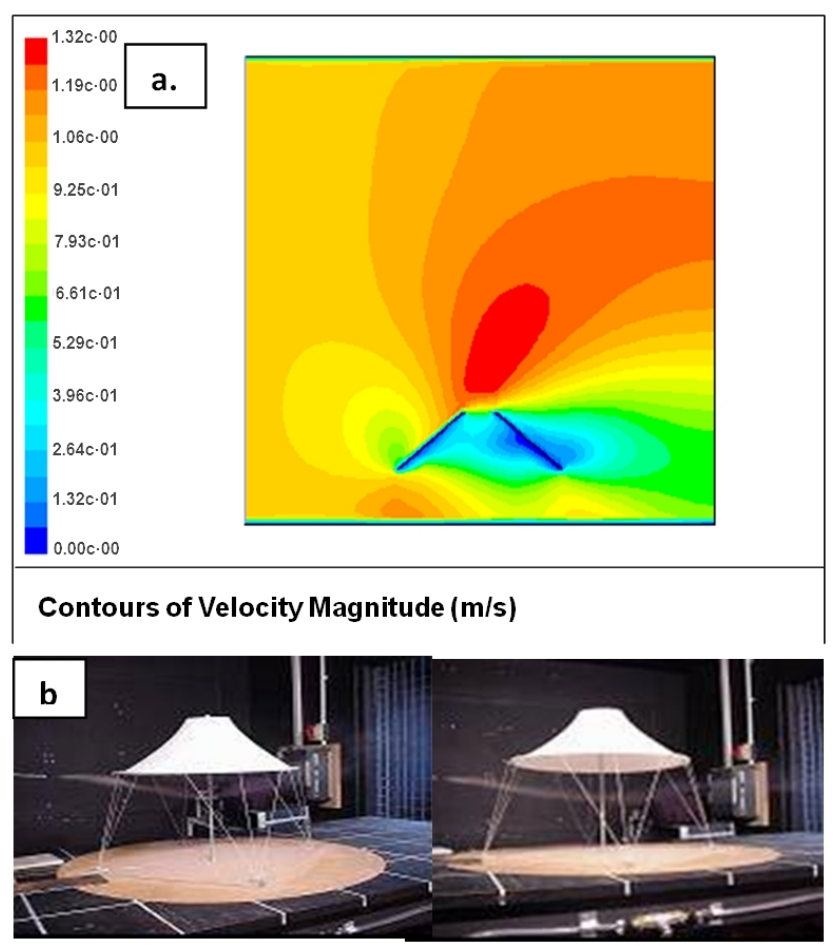

Figure 3. Contours of Velocity Magnitude of a 2D $17 \mathrm{~cm}$ high cone; Wind tunnel exp. showing the effect on airflow of a conical membrane with closed apex

\subsection{CFD Investigation; 3D Modelling}

The significant qualitative resemblance between the $2 \mathrm{D}$ CFD modelling and the wind tunnel data, along with the motivating results and findings from the wind tunnel experiments indicated that it would be worth extending the investigations to 3D. Fig. 4 shows grid representing the working area of the wind tunnel containing a conical TMS model. Fig. 4 depicts how the grid or mesh density is very much different between the mesh in the volume around the cone and the mesh density of the cone itself. The grid is generated in one of the drawing tools used for FLUENT called Gambit $[16,26]$, and then exported to FLUENT. The mesh used in these models is the hexa-tetra, where both hexagon and tetrahedral cells are used to generate the final mesh as shown if Fig.5. In each model there are 
approximately 30,000 cells, 60,000 faces and 50,000 nodes.

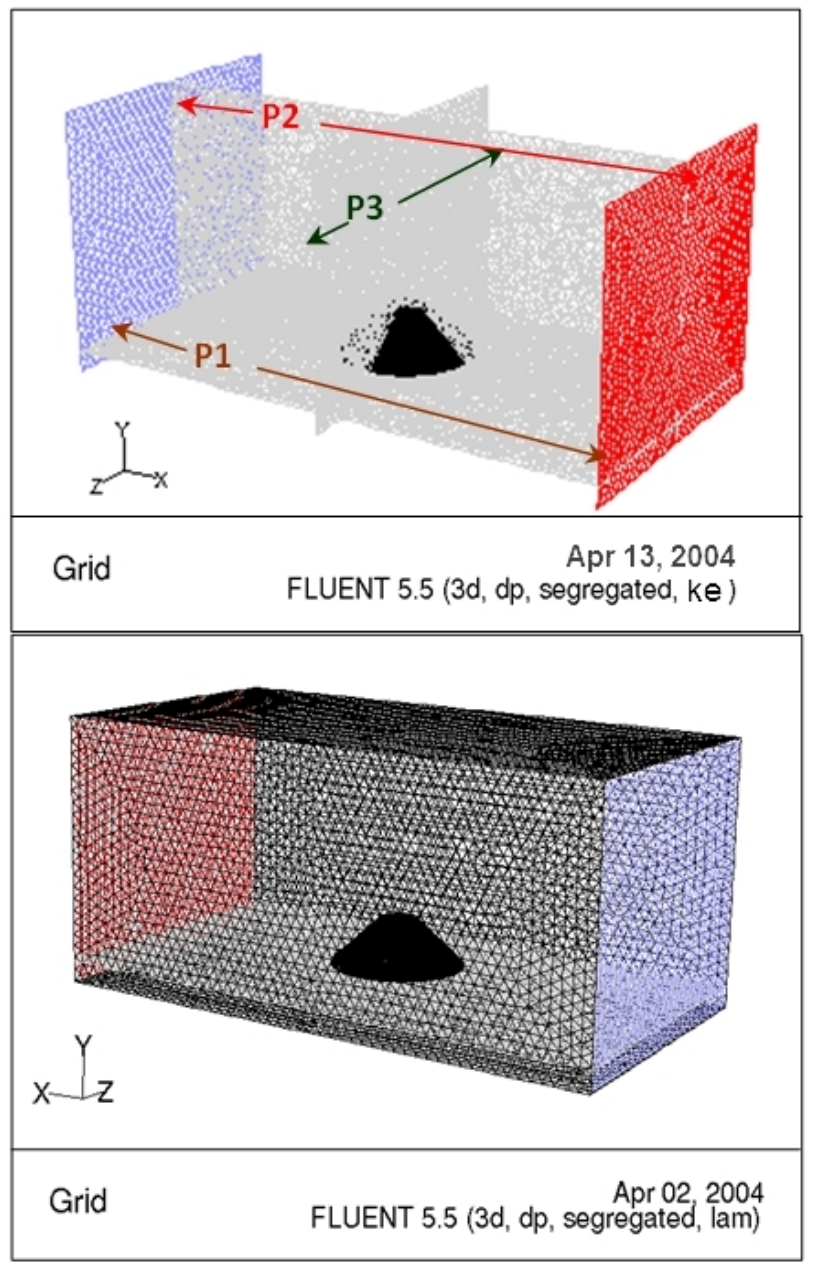

Figure 4. Depicts the $3 \mathrm{D}$ model of a $17 \mathrm{~cm}$ high closed apex cone and meshing of the model in FLUENT

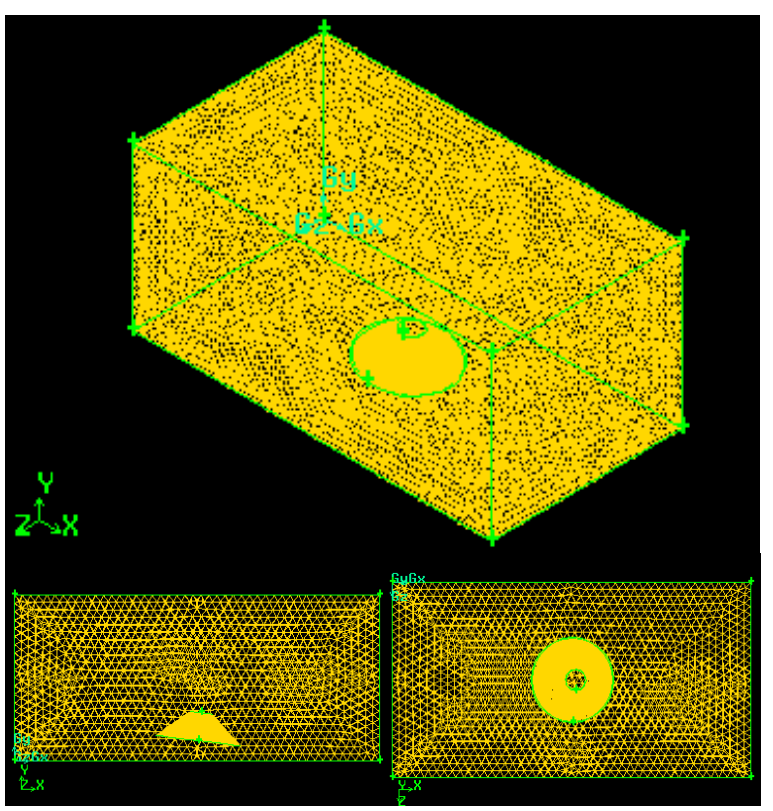

Figure 5. Diagrams depict the grid display of the cone and the volume around it for a $17 \mathrm{~cm}$ high cone tilted away from the wind (wind direction coming from the left)
A number of models were built representing the different cases given in Figure 2. The approach to grid design in flow problems around bluff bodies is to maximise the grid density (i.e. minimize grid spacing) in the areas where the gradients of the flow variables are likely to be greatest. In the current investigations these regions are the regions around the cone itself, (i.e. close to the surface, under and over it) where flow separation and change of air velocity flow and air pressure takes place. Fig. 4 also presents the planes on which the velocity magnitude and other contours were displayed in all cases, which is the horizontal plane (P1) and the two vertical planes (P2) and (P3) passing through the mid axis of the cone in both directions, the blue plane displays the inlet and the red plane displays the outlet.

Fig. 6 shows the contours of velocity magnitude $(\mathrm{m} / \mathrm{s})$ (unfilled contours) for two of the cases tested in FLUENT: the $17 \mathrm{~cm}$ high open and closed apex cones respectively. It is obvious that the trend in the two graphs is similar with slight differences in the air velocity rates underneath the cones. The airflow tends to deflect downward on the windward side of the cone; this is pronounced more vigorously in the case of the closed apex cone. Also air velocity is seen to increase on the windward of the cone, this more obvious in the case of closed apex cone, this increase is not so high and thus is difficult to cause uncomfortable situation.

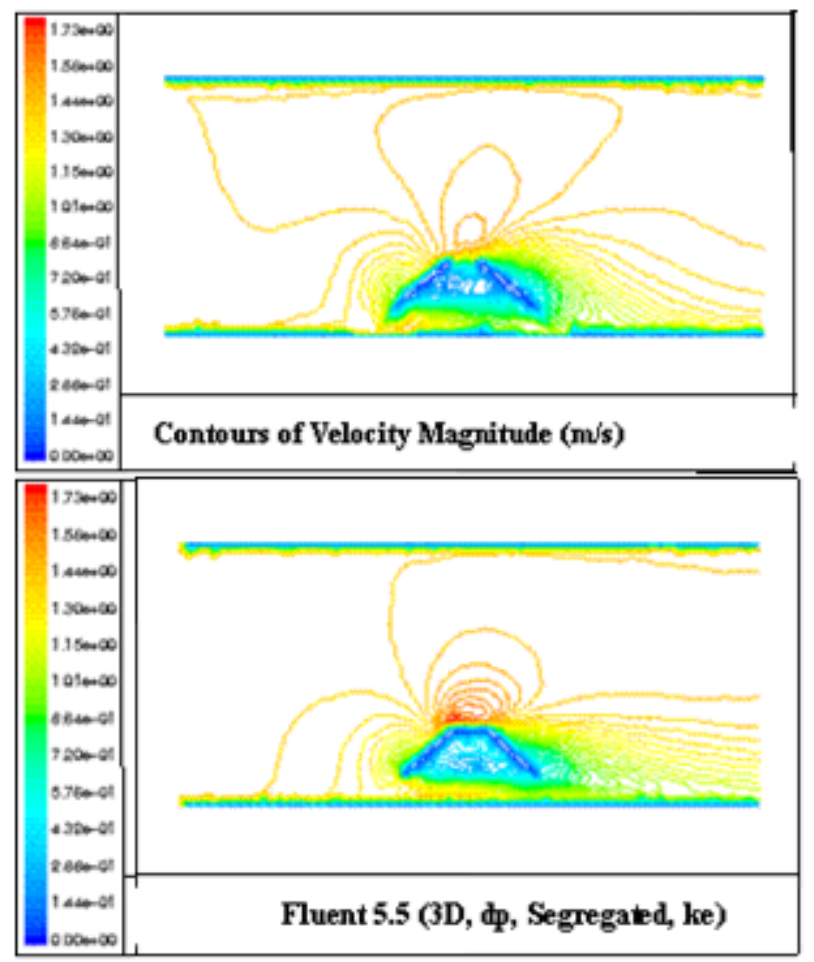

Figure 6. Contours of velocity magnitude for vertical planes on the mid axis of a $17 \mathrm{~cm}$ high opened and closed apex cones respectively at $12 \mathrm{~cm}$ high from the ground for 3D models

The air velocity increases significantly over the top of the closed apex cone, where as in the open apex case, the air decreases first in a very narrow slice on top of the apex then 
increases gradually. The highest increase in air velocity is monitored above the apex but this is more obvious in the case of closed apex cone. This phenomenon can be utilized according to the requirements of the project. The $2 \mathrm{D}$ and 3D modelling demonstrates similar qualitative behaviour to the wind tunnel testing that implies that the CFD model used can be reasonably reliable.

Fig. 7 clearly identifies how the air velocity increases significantly in the area underneath the inverted cone, especially in the region just under the base of the cone and its vicinity where large air velocities can be seen, i.e. in the semi-enclosed or inhabited space. Though a slight increase in the air velocity is seen in the case of $17 \mathrm{~cm}$ high straight cone shown in Fig. 6, the inverted case shows far larger air velocity increases. On top of the structure the airflow is seen to decrease which is the contrary to what happens in the case of straight closed cones seen in Fig. 6. From Fig. 6 and 6 it is obvious that air velocity decreases significantly inside the cone itself which is similar to what can be seen in the inverted cones in Fig. 7. Opposite airflow trends were monitored for both the straight closed apex cone in Fig. 6, and the inverted closed base cone shown in Fig. 7 at $17 \mathrm{~cm}$ high.

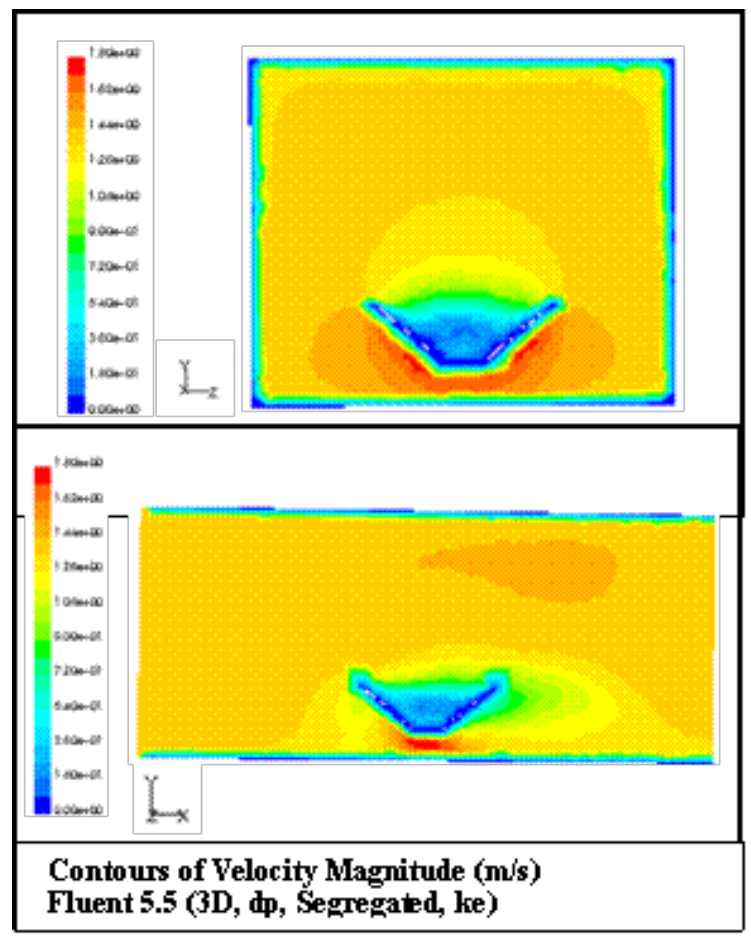

Figure 7. Contours of velocity magnitude (y-z plane)and the (y-x plane) respectively, for an inverted closed base $17 \mathrm{~cm}$ high cone at $12 \mathrm{~cm}$ high from the base for a vertical plane passing the mid axis of the cone parallel to the airflow

Table 1 presents the contours of velocity magnitude over two different planes for three of the cases tested in CFD modelling. The three studied cases presented in Table 1 are the flat disc, the $3 \mathrm{~cm}$ high closed apex cone, and the 17.5 $\mathrm{cm}$ high closed apex cone all at a height of $12 \mathrm{~cm}$ from the ground. It can be clearly seen from Table 1 that the increase of the height of the cone from a flat disc to a $17 \mathrm{~cm}$ high cone significantly affects the airflow behaviour and pattern under the structure and in its vicinity. In the case of flat disc there is a little change in the air velocity monitored underneath the structure and also in its wake where the air velocity decreases slightly. The placement of the cones significantly affects the airflow speed as also seen in all the other cases. In the case of $3 \mathrm{~cm}$ high cone, as seen on the horizontal plane, the air velocity tends to decrease around the circumference of the cone then increases slightly in the middle area but the air velocity monitored is still lower than that in the case of flat disc. In the vertical sections shown for all conical cases presented in Table 1, air velocity increases on the top of the apex and the size of the region where the air velocity increases, increases with the raise in the height of the cone. For the horizontal sections shown for the $17 \mathrm{~cm}$ high closed apex cone it can be seen that the air velocity increases significantly on the circumference of the cone in the direction of the airflow with a slight decrease of the air velocities in the area of the middle region of the cones. In the vertical planes it is clear that in all the cases presented in Table 1 a slight decrease in the air velocity in the middle of the semi-enclosed space takes place, which is pronounced in a larger region with the increase in the height of the cone as illustrated from the horizontal planes as well.

Table 1. Contours of velocity magnitude over horizontal (x-z plane) and vertical ( $y$-x plane) planes for straight closed apex cones with different heights

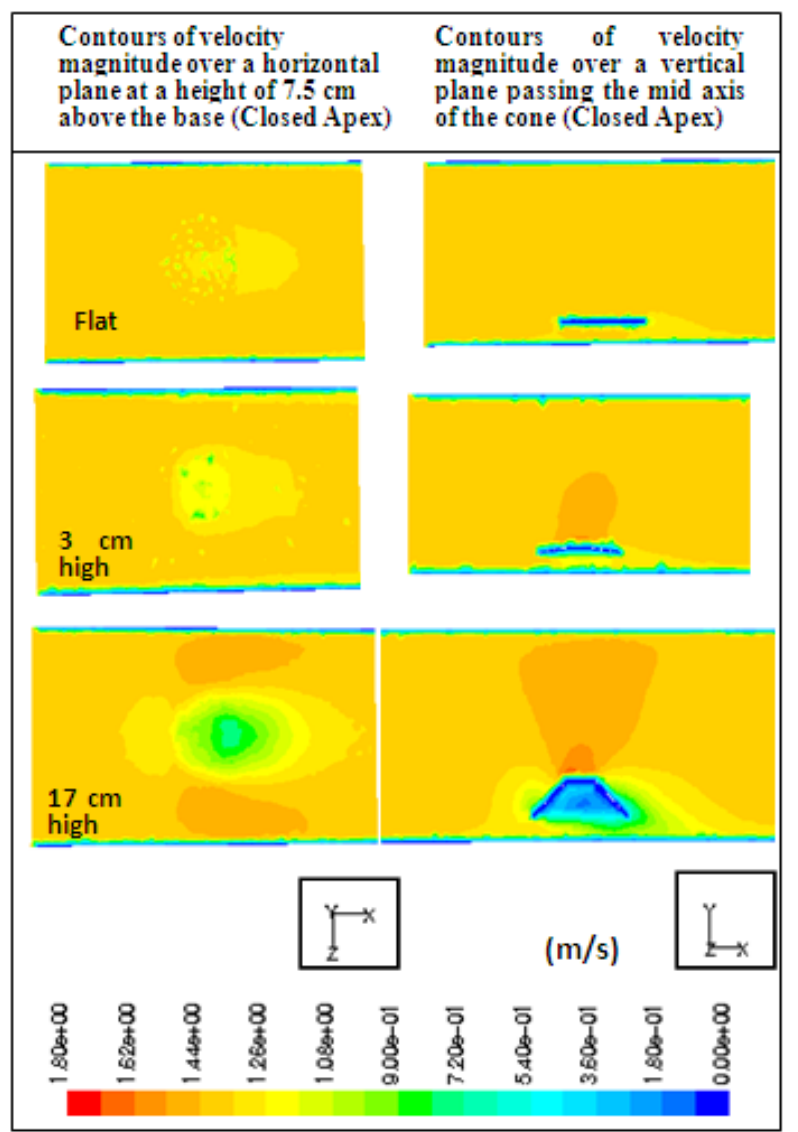


Table 2. Contours of velocity magnitude over horizontal (x-z plane) and vertical ( $y$-x plane) planes for inverted closed base cones with different heights

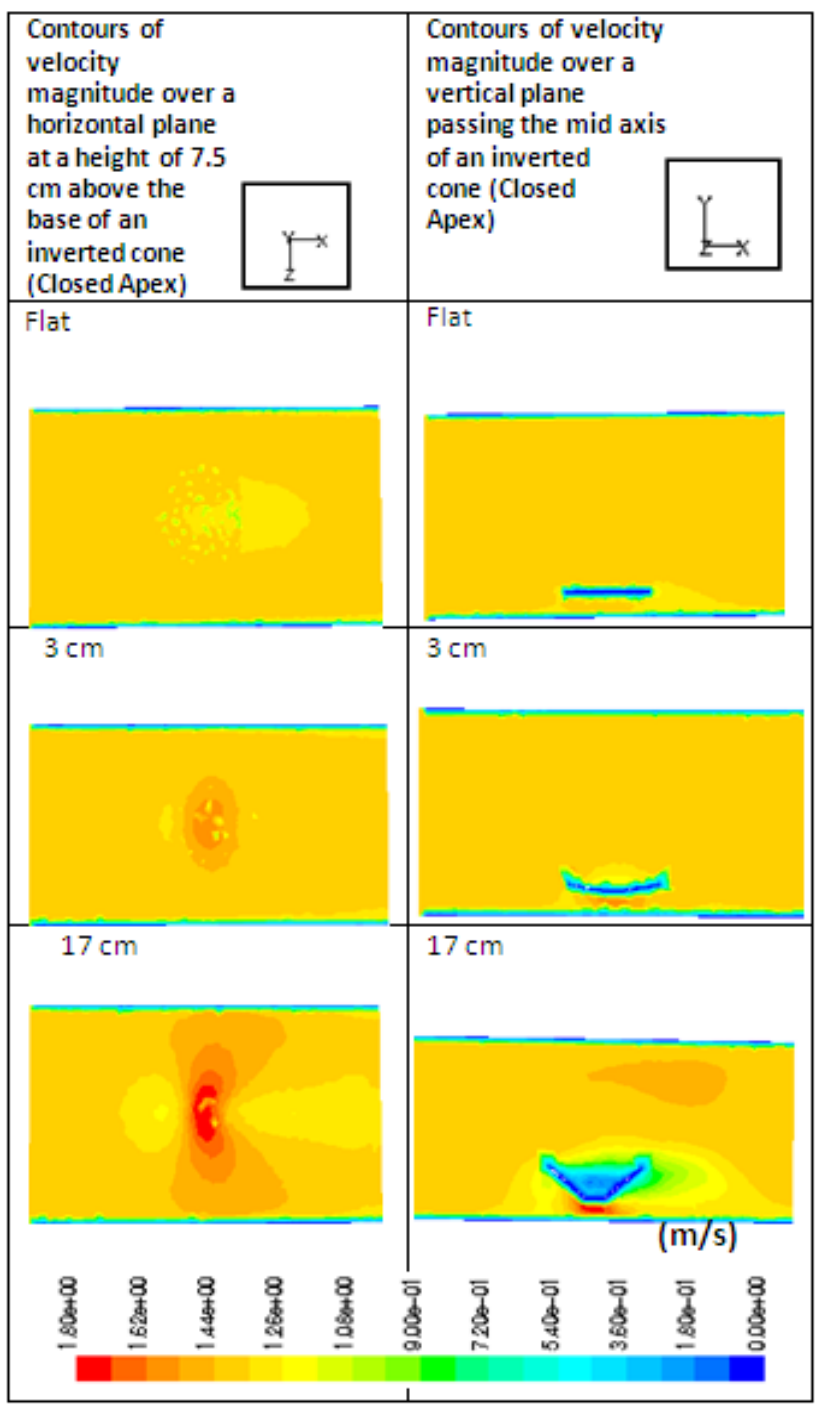

In Table 2 the contours of velocity magnitude similar to those shown in Table 1 are presented for inverted cones. This comparison is made between the flat disc and two inverted closed base cone at $3 \mathrm{~cm}$, and $17 \mathrm{~cm}$ high with all cones positioned at a height of $12 \mathrm{~cm}$ from the ground. Increasing the height of the inverted cones led to an increase in the air velocity underneath the semi-enclosed space which is pronounced in a larger region with the increase in the height of the cone. In the case of inverted cones higher air velocities are achieved underneath the cones than that of the flat disc or the straight cones presented in Table 1.

Comparing Table 1 and 2 it can be seen that there is a major difference in behaviour between the straight cones and the inverted cones, as the air velocity increases significantly underneath the inverted cones, whereas in the straight case the air velocity decreases slightly in the area underneath the structure. In the case of the inverted cones studied the area of the region where the air velocity is seen to increase, increases with the increasing height of the cone.
Tables 3 and 4 compares the contours of velocity magnitude over a vertical plane (y-z plane) passing through the mid axis of the cone for opened and closed apex straight cones and opened and closed inverted cones respectively. In Table 3 the cases when there is no cone and when there is a flat disc are also presented.

Table 3. Contours of velocity magnitude over vertical (y-z plane) planes for straight opened and closed apex cones with different heights

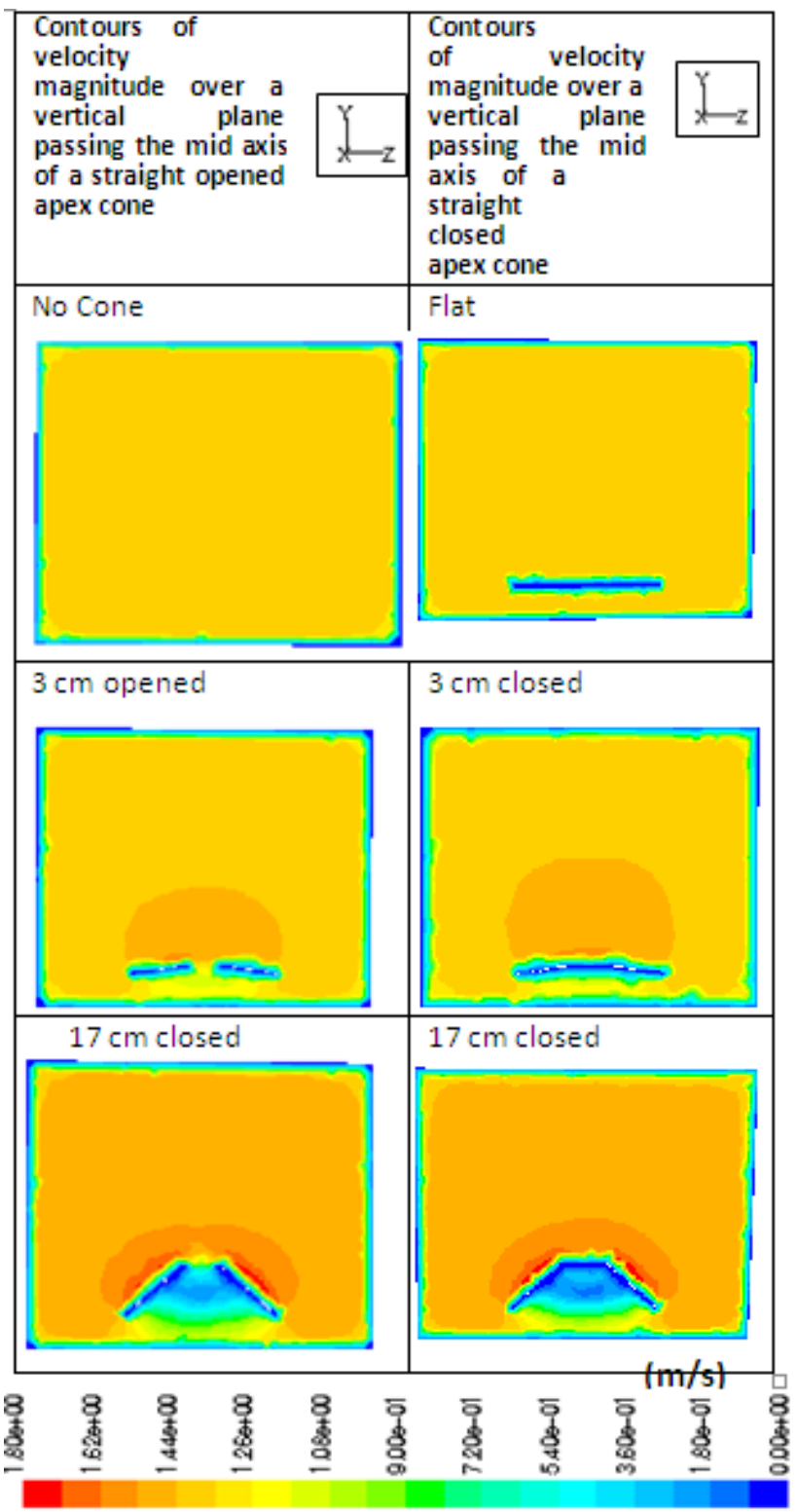

It is clearly seen that the two tables present opposite trends to one another in terms of the airflow pattern and velocity. In the case of straight cones higher air velocities occur on top of the apex of the cone. The contrary happens in the inverted cones where lowest air velocities occur on top of the cone and the highest air velocities are achieved under the base of the cones. Opening the apex of the cones decreases the area of the region were the air velocity is increased. It is concluded from these two tables that in projects where higher air velocities are required in the 
occupied zone it is beneficial to use inverted cones in preference to straight cones.

Table 4. Contours of velocity magnitude over vertical planes (y-z plane) for inverted opened and closed base cones with different heights

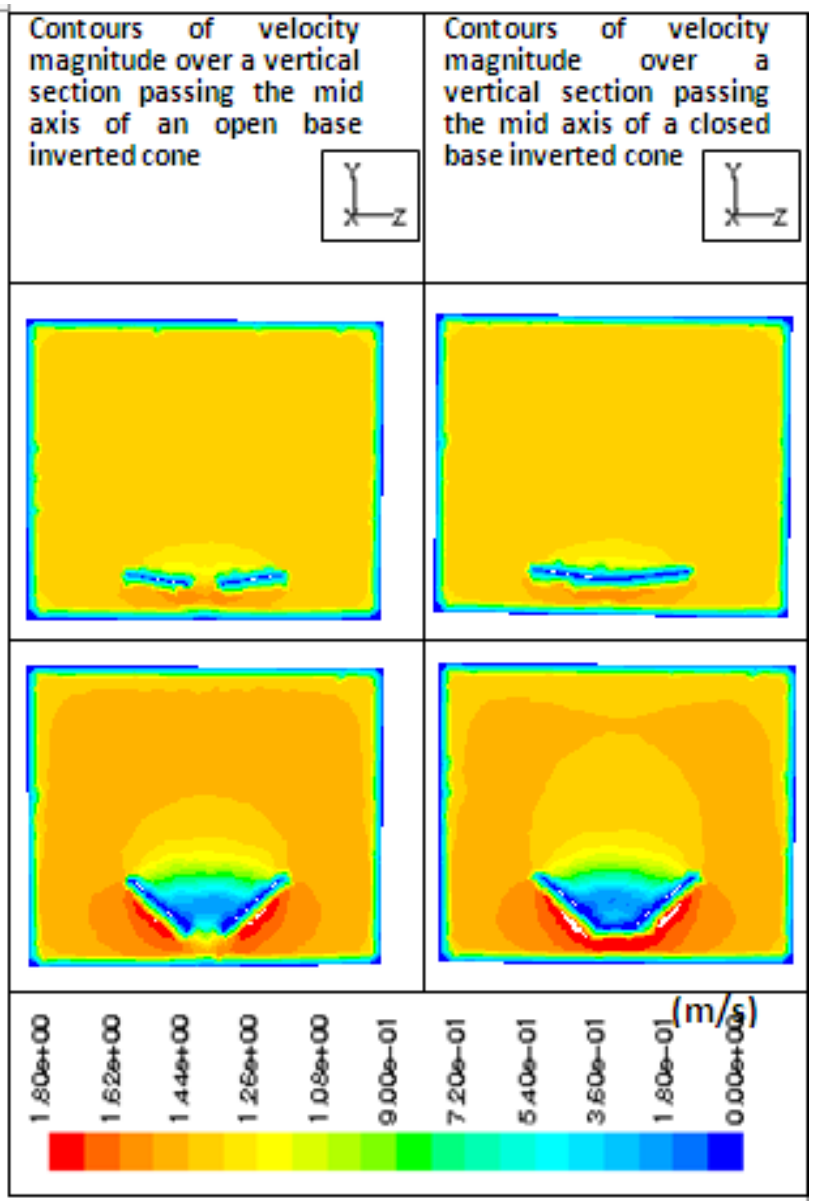

The change in air velocity that takes place under the cones can be used according to the requirements of the projects where the straight cones can be used where lower speeds of air is required underneath the structure. The increase of air velocity on the top of the apex of straight cones can be used in front of buildings where higher speeds is required to flow through higher floors or when higher speeds are required in the vicinity or around the structure. Another idea is the placement of a wind turbine on top of the straight cone as a means of the integration of Renewable energy techniques in the Built environment and our daily architectural design.

In Table 5 the contours of velocity magnitude over vertical planes in the $\mathrm{x}$-axis direction for eight different cases of tilted opened and closed apex $17 \mathrm{~cm}$ high cones with different tilt directions are presented. The cases tested are $17 \mathrm{~cm}$ high cones tilted away from the wind with open and closed apex (TAO and TAC respectively), $17 \mathrm{~cm}$ high cones tilted to the left (north) of the airflow direction of the wind with open and closed apexes (TNO and TNC respectively), $17 \mathrm{~cm}$ high cones tilted to the right (south) of the airflow direction of the wind with opened and closed apexes (TSO and TSC respectively), and finally $17 \mathrm{~cm}$ high cones tilted towards the wind with opened and closed apexes (TTO and TTC respectively),are shown respectively in Table 5.

Tilting the cone away from the wind (at 8 and $16 \mathrm{~cm}$ high) shows similar trends to what is seen for the straight cones with only slight differences. Air velocity tends to decrease towards the leeward side of the inhabited zone under the structure and increase just on top of the apex. Simulations carried out with the apex open show slightly lower velocities underneath the cones than that of the closed apex. Also the increase in air velocity on top of the apex in the TAO case although high, it is still relatively lower than that monitored for the TAC case.

Table 5. Contours of velocity magnitude over vertical (y-x plane) planes for tilted opened and closed apex cones with different heights

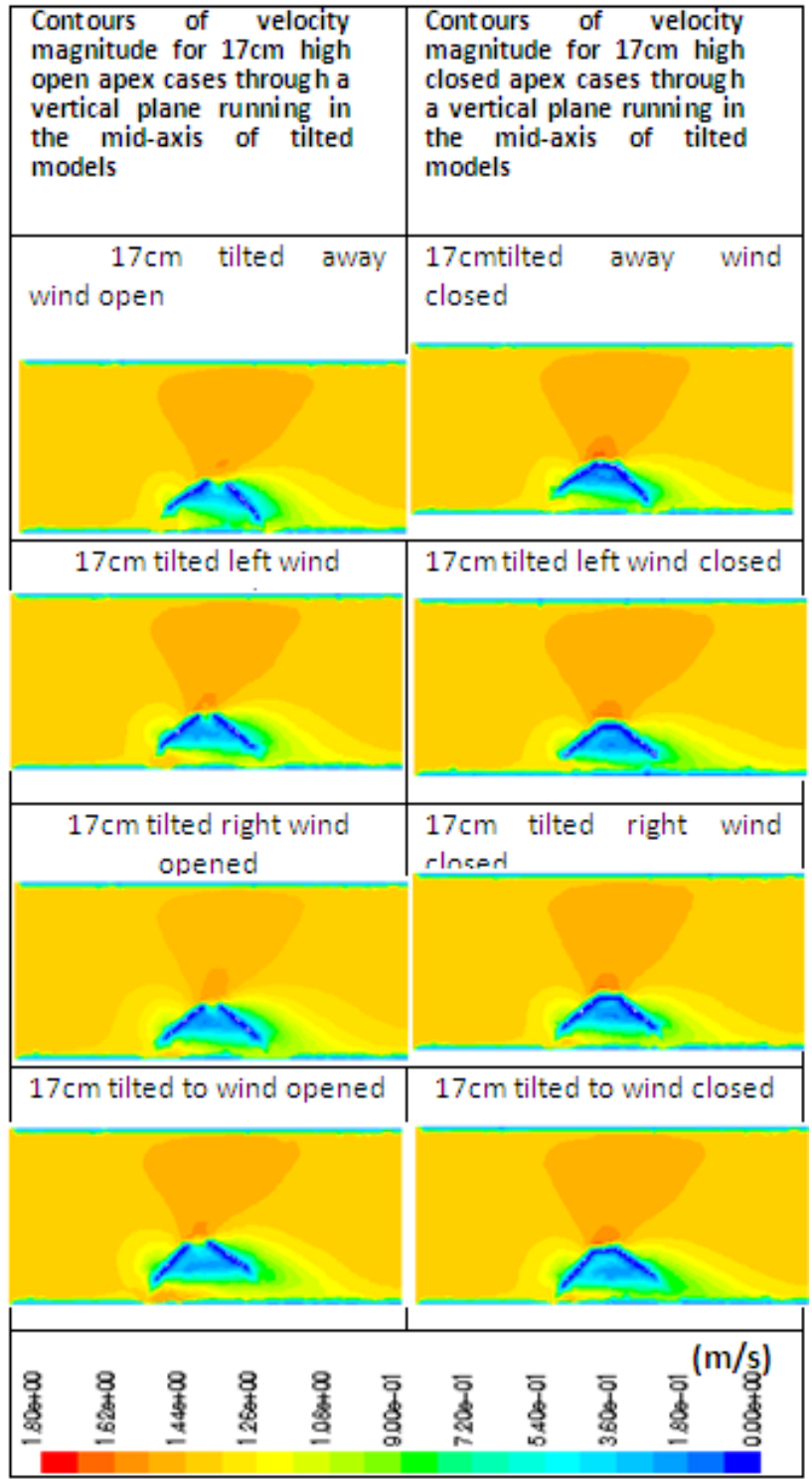

In the case of tilting the structure towards the wind (TTO or TTC) it is seen that air velocities increases in the windward side of the structure, which is more pronounced 
in the case of TTO.

On top of the apex air velocities are also seen to increase with higher increases monitored on top of the TTC case compared with TTO, similar to the trend shown in TAC.

Table 6. Contours of velocity magnitude for horizontal (x-z plane) planes for tilted opened and closed apex cones with different heights

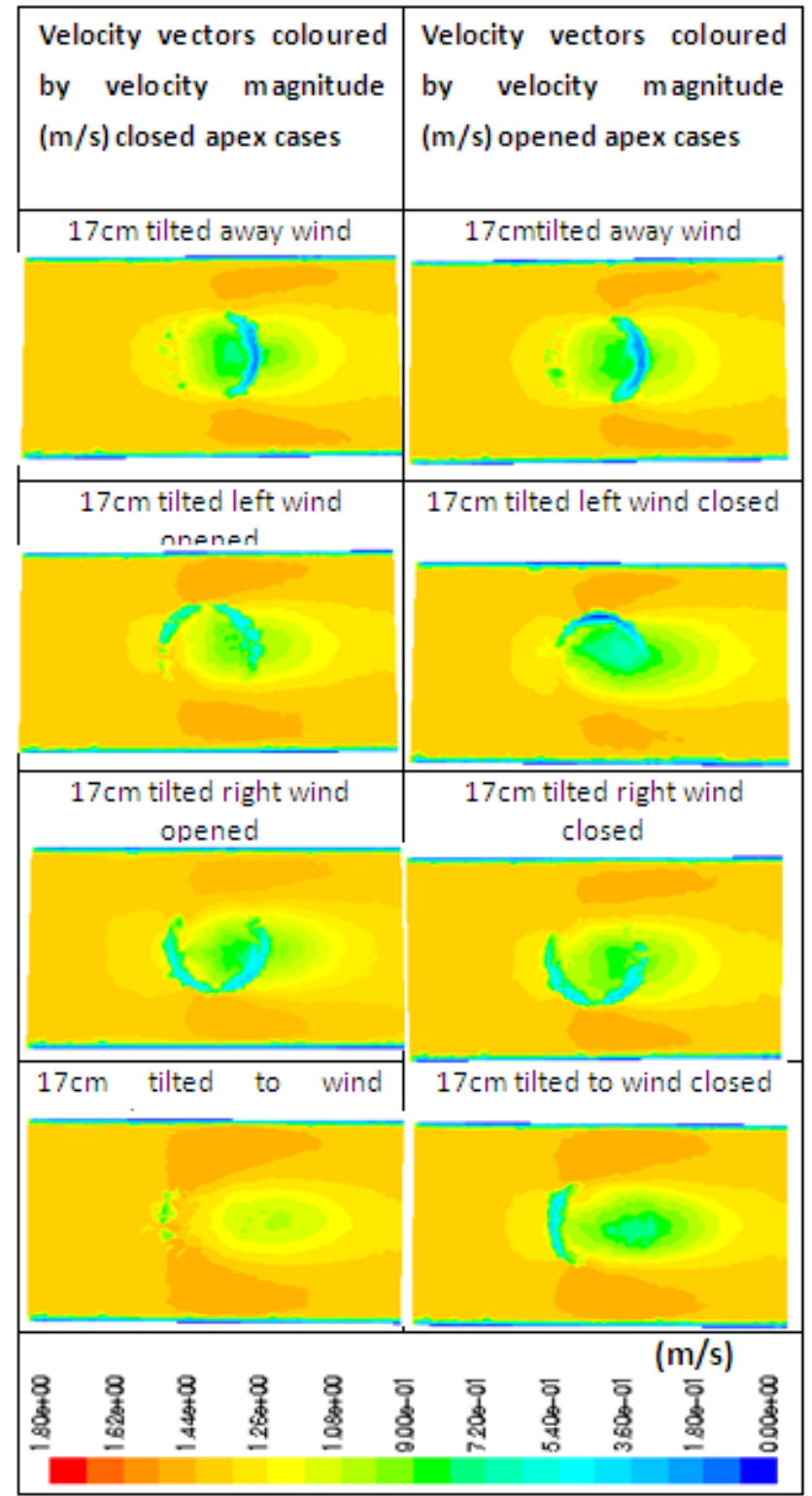

Table 6 shows the same eight cases presented in Table 5 but in a different plane ( $\mathrm{x}-\mathrm{z}$ plane) at $7.5 \mathrm{~cm}$ high from the ground. It is clearly seen from the graphs in Table 7 that the air velocity tends to decrease underneath the area in which the cone is close to the ground, thus when tilted towards the wind higher decrease in the air velocity is seen underneath the windward side of the cone, and when tilted away from the wind, the lower air velocities monitored are to the leeward side of the area underneath the cone.

The highest air velocities are achieved in the cases of tilting the structure towards the wind (TTO and TTC) and specifically with opened apex cones and on both sides of the cone itself.

In Tables 7 and 9 a comparison of contours of velocity magnitude for vertical and horizontal planes of 1:20 and 1:1 scale straight closed apex and inverted closed apex conical model respectively are shown. In Tables 9 and 11 comparison is made between the velocity magnitude plot of 1:20 scaled model and the 1:1 scale model for the two cases presented in Tables 8 and 10 in order to assess the extent of effect the scaling of the actual size of the structure has on the airflow behaviour of the tested cases. The air velocity is plotted on the $\mathrm{X}$-axis and the position in the space is plotted on the $\mathrm{Y}$-axis.

Tables 8 and 10 are meant to reinforce the data presented in the other two tables and these two sets of tables of plots and contours can be cross referenced to be compared. The graphs in Table 8 of the velocity magnitude for a 1:20 scaled straight closed apex conical model and the 1:1 straight closed apex cone depicts similar trends in the airflow pattern and velocity in both the cases.

Table 7. Comparison of contours of velocity magnitude for vertical and horizontal planes of 1:20 and 1:1 scale straight closed apex conical model

\begin{tabular}{|l|l|}
\hline $\begin{array}{l}\text { Contours of velocity } \\
\text { magnitude for a 1:20 } \\
\text { scaled straight conical } \\
\text { model }\end{array}$ & $\begin{array}{l}\text { Contours of velocity } \\
\text { magnitude for a 1:1 } \\
\text { straight conical model }\end{array}$ \\
\hline & \\
\hline & \\
\hline
\end{tabular}

The real air velocity was obtained from the following equation and was used in the simulation of the full scale model as follows:

"Full Scale model with velocities calculated to the scaled model where

$\operatorname{Re}($ real $)=\operatorname{Re}($ model $)$

The Eqn. 1 presented in this paper of the Reynolds Number calculation is used in the above equation.

Thus with the calculation $\mathrm{V}(\mathrm{real})=0.89 \mathrm{~m} / \mathrm{s}$ " 
Table 8. Comparison of Velocity Magnitude plot for vertical and horizontal planes of 1:20 and 1:1 scale straight closed apex conical model

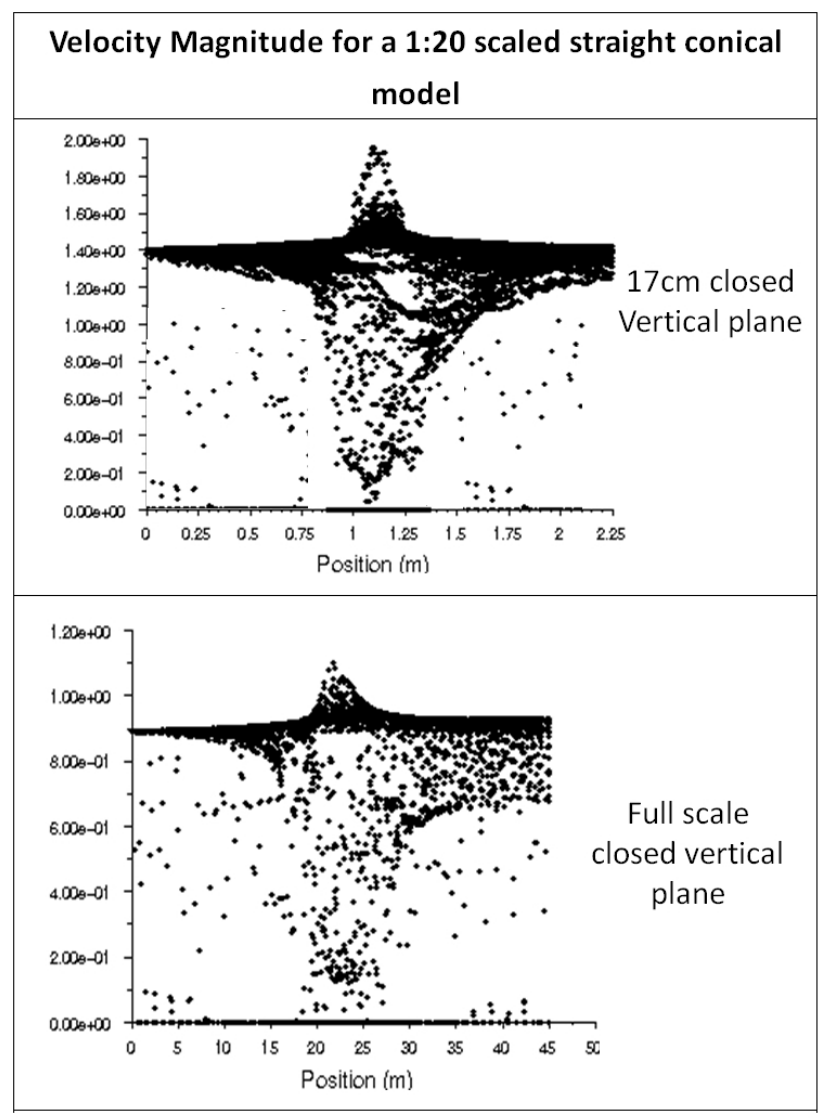

Velocity Magnitude for a 1:1 straight conical model
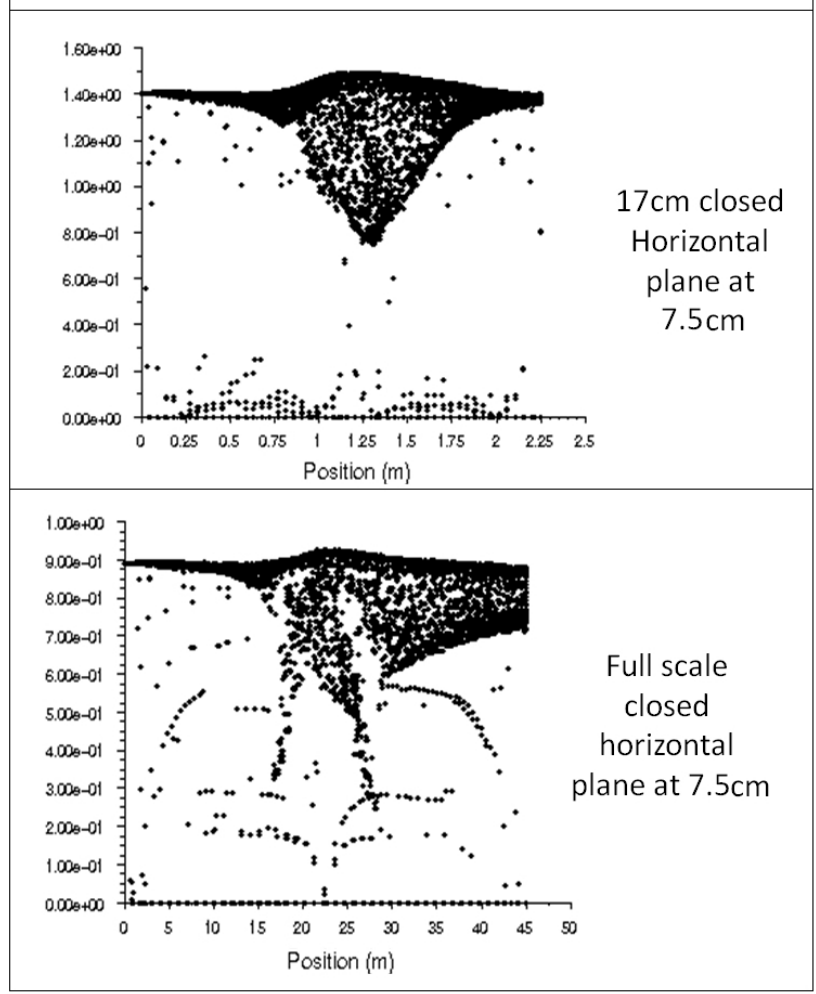

Table 9. Comparison of contours of velocity magnitude for vertical and horizontal planes of 1:20 and 1:1 scale inverted closed apex conical model

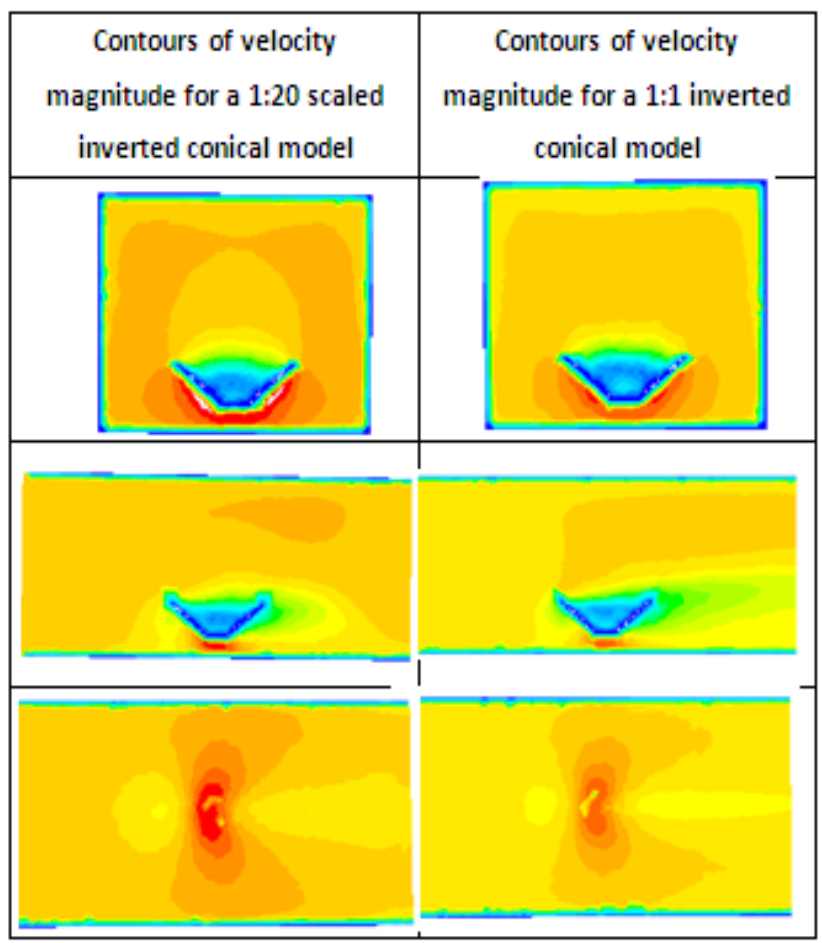

Table 10. Comparison of Velocity Magnitude plot for vertical and horizontal planes of 1:20 and 1:1 scale inverted closed base conical model Where $\perp=$ Arrows indicates a qualitative comparison.

Velocity Magnitude for a 1:20 scaled inverted conical model
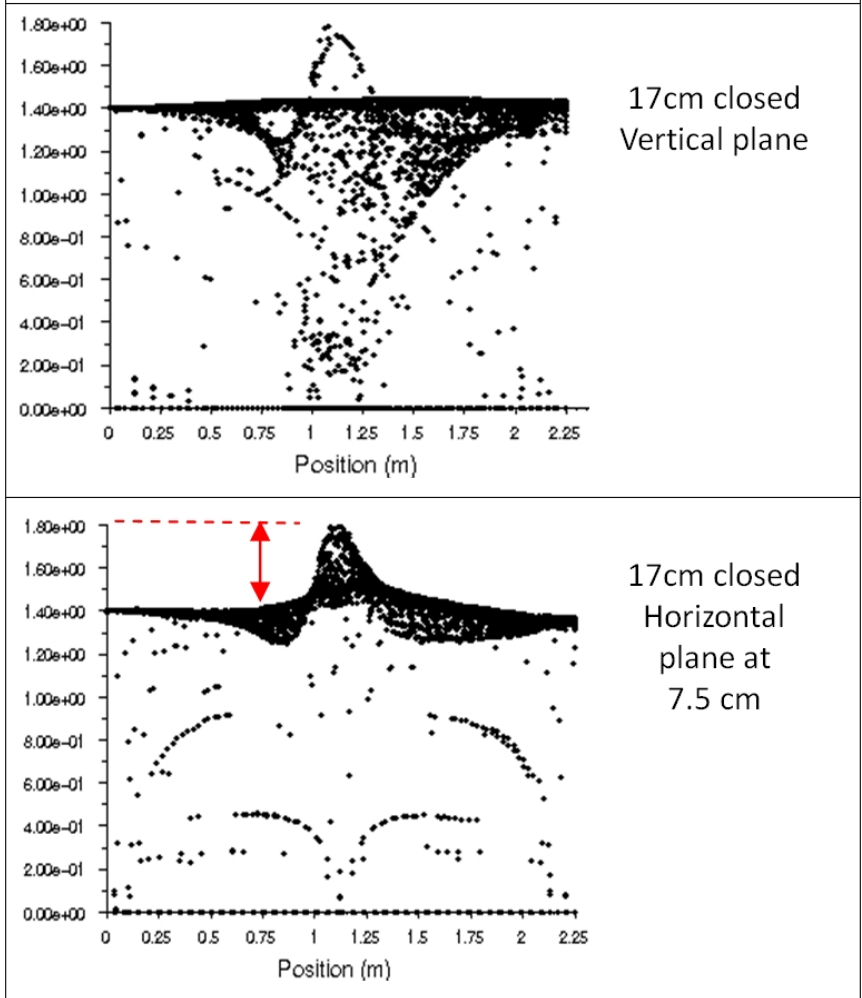


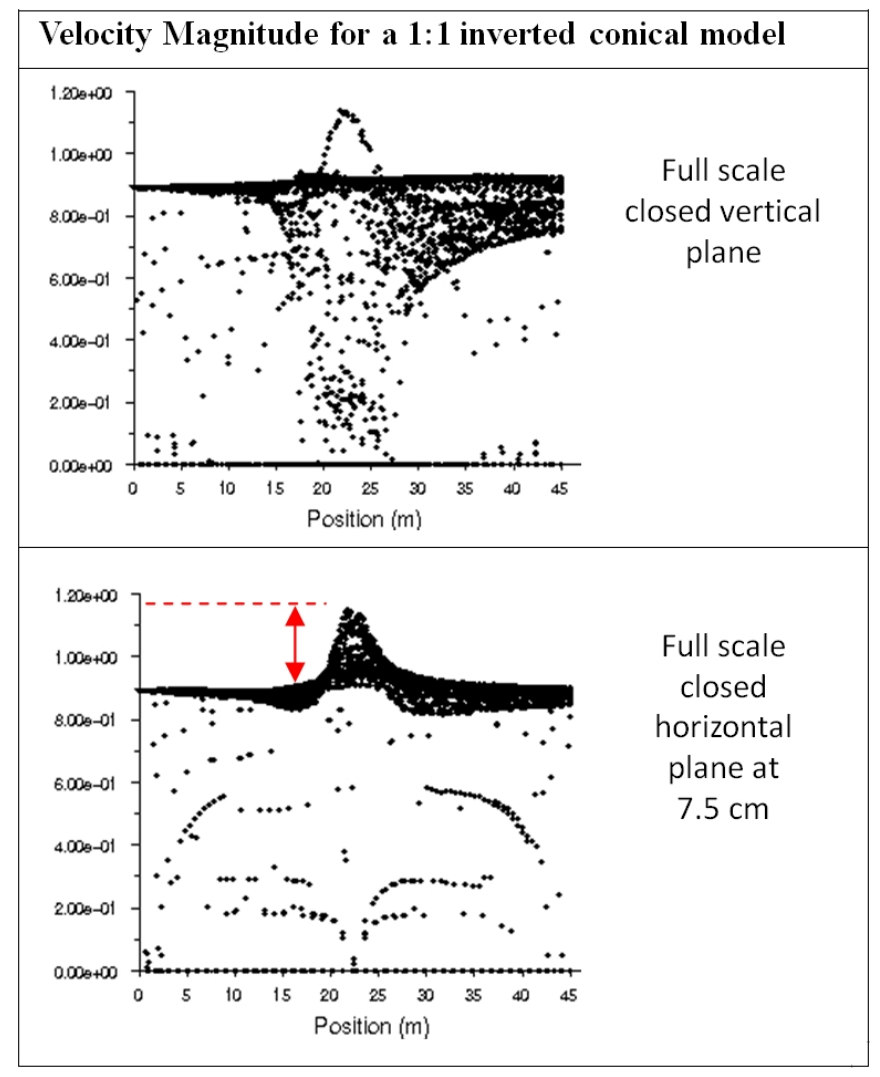

From Tables 8 and 10 it is clear how the 1:20 scaled model agrees closely to the results achieved from the 1:1 model on a qualitative basis. In Tables 8 and 10 both 1:20 scaled model and the 1:1 scale model follows similar patterns of flow. Qualitatively analysing the graphs the proportion of increase in air velocity in both the cases is very similar. These concluding results strengthened the reliability of the CFD modelling undertaken in this research, and demonstrated that the 1:20 scaled model results in CFD agrees with that of the real scale tests.

In Table 9 it is clearly seen that in the vertical plane air velocity is seen to increase where the structure is placed on the top of the apex, and that not much change in the air velocity is seen on the horizontal plane with a slight decrease in the air velocity. This behaviour is the contrary of what takes place in the inverted cases in Table 10 where air velocity is seen to increase significantly underneath the cones in the horizontal plane.

\section{Conclusion}

The study presented in this paper illustrates that the airflow pattern and speed underneath and above the semi-enclosed spaces is clearly affected by the placement of the TM conical structure in the space, which displays a completely different behaviour from that achieved by a flat disc of the same diameter. The empirical study used CFD investigation techniques using FLUENT 5.5, and the results reported were validated using similar scaled models in
Wind tunnel experiments.

A cross case analysis is carried out and the results shows that higher airflow velocities are achieved underneath the structure and in its immediate vicinity under certain conditions. For instance, with inverting the cones and with increasing its height. Also the area on both sides of the straight cones predicts higher air velocities compared with the cases without a cone and when a similar flat disc is placed in position of the cone. Air velocities are also seen to increase on top of the apex of straight cones and this increase is directly proportional to the height of the cone; this is the contrary to what is seen to happen in the case of inverted cones.

The increase in the air velocity underneath and in the vicinity of the semi-enclosed space depending on the requirements of the projects modifies the microclimate and improves human comfort level within the enclosed or semi-enclosed space, particularly in hot arid climates. and to ascertain the potential of conic membranes with different configurations for modifying the microclimate and improving human comfort within the enclosed or semi-enclosed space. The use of these structures with the right height and orientation along with well designed evaporative cooling techniques (such as ponds, fountains, micronizers) or other passive cooling systems will enhance the comfort level within the spaces semi-enclosed by TMS. The increase in air velocities increases the movement of air around the human body, and even with very high temperatures, help in evaporative cooling of the human body, and increasing the environmental comfort within the space. Concomitantly, these structures can be successfully used as microclimate modifiers in hot arid regions.

The application of the results presented in this paper, will further promote the use of the buildings semi-enclosed by TMS in moderate and hot dry climates. This not only reduces the energy required for day-lighting the space by TMS but also reduces energy used for the cooling plants as it enhances the airflow rates and consequently natural ventilation within the space.

The results indicate the need for further research in this area, in order to fully realize the potential benefits offered by TMS for modifying airflows underneath them and in their vicinity and for their use as microclimate modifiers. It is believed that it is of vital importance to test different forms and orientations of the conical roof or fabric form before adopting them in a project and to fully understand the effect the form have on the environmental behaviour of TMS.

\section{REFERENCES}

[1] Frei Otto, Lightweight Construction - Natural Design, complete works of German architect Frei Otto, Basel, Switzerland:, Birkhauser Verlag AG, First edition, 2005. 
[2] Elnokaly, A., Chilton, J., and Wilson, R., Environmental performance of spaces enclosed or semi-enclosed by fabric membrane structures. In: International Conference on Textile Composites and Inflatable Structures, Structural Membranes 2003, June 2003, Barcelona, Spain, 2003.

[3] Elnokaly, A., Chilton, J. and Wilson , R., CFD investigation of airflow around conic tensile membrane structures . In: IASS 2004, Shell and Spatial Structures from Models to Realization, September 20-24, 2004, Montpelier, France, 2004.

[4] Jiang H. and Akira H., Measurement and evaluation of the summer microclimate in the semi-enclosed space under a membrane structure Building and Environment Volume 45, Issue 1, January 2010, Pages 230-242, 2010.

[5] Elnokaly, A., and Chilton, J., and Wilson, R., Use of fabric membrane topology as an intermediate environment modifier. In: The 20th conference of Passive and Low Energy Architecture, PLEA 2003, Santiago, Chile, November 9-12, 2003, pp. E-17., November 9-12, 2003, Santiago, Chile, 2003.

[6] Campbell, J. "Environmental considerations of lightweight structures" The Arup Journal, Vol. 15, No. 3, October 1980, p. $25 ., 1980$

[7] Holst, S., Schuler, M. "Innovative energy concept for the New Bangkok Airport" Proceedings of the TensiNet Symposium, 19-20 September 2003, Brussels, pp. 150-167, 2003.

[8] Kim, B.S., Roh, J.W., Kim, T.Y. and Kim, K.H., The indoor environment measurement analysis of arcade-type markets in Korea Journal of Asian Architecture and Building Engineering, 5 (1), pp. 191-198 View Record in Scopus | Full Text via CrossRef | Cited By in Scopus (3), 2006.

[9] Mistriotisa, A. and Castellanob, S., Airflow through net covered tunnel structures at high wind speeds Biosystems Engineering Volume 113, Issue 3, November 2012, Pages 308-317, 2012

[10] Elseragy, A. and Elnokaly, A., Assessment criteria for form environmental performance of building envelope in hot arid climates. In: Conference on Passive and Low Energy Architecture, 22-24 November 2007, National University of Singapore, Singapore, 2007.

[11] H. Berger, Light structures, Structures of light: The art and engineering of tensile structures. Basel, Boston, Berlin, 1996.

[12] Wu, H., Boonyatikarn, S. and Engen, W. "The Stratification in fabric roof structures a strategy of energy conservation and system design". International Symposium on Architectural Fabric Structures, AFSF, 1984, pp. 192-196, 1984.

[13] Broderick, C.R. and Chen, Q., A simple interface to CFD codes for building environment simulations. Proceedings of the seventh international IBPSA conference, Building simulation, 2001 Aug 13- 15, 2001, Rio De Janeiro, Brazil, 2001.

[14] Cunningham, D., Investigating The Effects Of Resistance Pathways On Air Flow Through Naturally Ventilated Buildings, Proceedings of the IBPSA, BS2012, 2012 Available at: http://www.bso12.org/-proceedings/papers/2B3 .pdf, Accessed July 24, 2013
[15] Stavrakakis, G., Natural cross-ventilation in buildings: Building-scale experiments, numerical simulation and thermal comfort evaluation. Energy and buildings, 40(9), pp.1666-1681, 2008. Available at: http://www.sciencedirect.com/science/article/pii/S03787788 0800056X [Accessed March 8,2012].

[16] Fluent Incorporated Network Services. FLUENT; The right answers in CFD [Web Page]. Available at: http://www.fluent.com/. (Accessed 2004 Feb 2).

[17] B.S. Kim, J.W. Roh, T.Y. Kim, K.H. Kim, G.P. Hong Air exchange rate analysis of the arcade-type traditional market using wind tunnel experiment and CFD model Journal of Asian Architecture and Building Engineering, 5 (1) (2006), pp. 161-167, 2006.

[18] Murakami S. Current status and future trends in computational wind engineering. Journal of wind engineering and industrial aerodynamics 1997; Vols: 67 \& 68, pp: 3-34, 1997.

[19] Lu, JWZ, Lun IYF, Lam JC. CFD investigation of airflow around objects with different shapes, Proceedings of the international building performance simulation association, IBPSA Conference. 1999.

[20] Elnokaly, A. and Elseragy, A., Environmental scrutiny of traditional Mediterranean forms for contemporary application (an empirical study). In: Euro-Mediterranean Regional Conference Traditional Mediterranean Architecture. Present and Future", July 12-15, 2007, Barcelona, Spain, 2007.

[21] Elnokaly, A. and Chilton, J. and Wilson, R., Airflow around conic tensile membrane structures. In: International Symposium on New Perspectives for Shell and Spatial Structures IASS-APCS, Taipei, Taiwan, October, 2003. pp: 210-212, October, 2003, Taipei, Taiwan, 2003.

[22] Fluent Inc., Fluent Users Guide, Fluent Inc.1993, Lebanon, U.S., 1993

[23] Tensinet; The communication network for tensile structure in Europe, [Web Page]. 2001; Available at: http://www.tensinet.com/index.php. (Accessed 2004 Jan).

[24] The Engineering Toolbox; Resources, tools and basic information for engineering and design of technical applications; Laminar, Transitional or Turbulent Flow? [Web Page]. Available at: http://www.engineeringtoolbox.co m/21_577.html. (Accessed 2003 Oct 5).

[25] Launder, BE, Spalding, DB. The numerical computation of turbulent flows, Computer methods in applied mechanics and engineering, Vol. 3 (No. 2): pp: 269-289, March, 1974.

[26] Fluent Inc. Ltd, Gambit CFD Pre-processor [Web Page], Available at http://www.fluent.com/software/gambit/, accessed 1 February, 2004. 